\title{
Early skin-to-skin contact between healthy late preterm infants and their parents: An observational cohort study
}

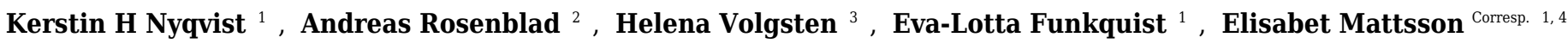 \\ 1 Department of Women's and Children's Health, Uppsala University, Uppsala, Sweden \\ 2 Center for Clinical Research Västerås, Uppsala University, Västerås, Sweden \\ 3 Department of Public Health and Caring Sciences, Uppsala University, Uppsala, Sweden \\ 4 Department of Health Care Sciences, Ersta Sköndal Bräcke University College, Stockholm, Sweden \\ Corresponding Author: Elisabet Mattsson \\ Email address: elisabet.mattsson@kbh.uu.se
}

Background: Skin-to-skin contact (SSC) is an important factor to consider in the care of late preterm infants (born between 34 0/7 and 36 6/7 completed weeks of gestation). The literature suggests that SSC between preterm infants and their mothers facilitates breastfeeding. However, more studies are needed to explore potential dose-response effects between SSC and breastfeeding as well as studies that explicitly investigate SSC by fathers among late preterm infants. The aim was to investigate the duration of healthy late preterm infants' SSC with the mother and father, respectively, during the first 48 hours after birth and the associations with breastfeeding (exclusive/partial at discharged), clinical and demographic variables.

Methods: This was an observational cohort study in which parents to healthy late preterm infants, born between 34 5/7 and 36 6/7 completed weeks of gestation, recorded duration of SSC provided by mother and father, respectively. Demographic and clinical variables were retrieved from the medical records and were used as predictors. Multiple linear regression analysis was used to assess the association between the predictors and the outcome, SSC (hours), separately for mothers and fathers.

Results: The mean (standard deviation [SD]) time per day spent with SSC with mothers $(n=64)$ and fathers ( $n=64)$, was 14.7 (5.6) and 4.4 (3.3) hours during the first day (24 hours) after birth and 9.2 (7.1) and 3.1 (3.3) hours during the second day (24 hours), respectively. Regarding SSC with mothers, no variable was significantly associated with SSC during the first day, while the mean (95\% confidence interval [CI]) time of SSC during the second day was 6.9 (1.4-12.4) hours shorter for each additional $\mathrm{kg}$ of birthweight $(p=0.014)$. Concerning SSC with fathers, the mean $(95 \% \mathrm{Cl})$ time of SSC during the first day was 2.1 (0.4-3.7) hours longer for infants born at night $(p=0.015), 1.7(0.1-3.2)$ hours longer for boys $(p=0.033), 3.2(1.2-5.2)$ hours longer for infants born by caesarean section $(p=0.003)$, and $1.6(0.1-3.1)$ hours longer for infants exclusively breastfed at discharge $(p=0.040)$. During the second day, the mean $(95 \% \mathrm{Cl})$ time of SSC with fathers was $3.0(0.6-5.4)$ hours shorter for each additional $\mathrm{kg}$ of birthweight $(p=0.014), 2.0(0.5-3.6)$ hours longer for infants born during night-time $(p=0.011), 2.9(1.4-4.4)$ hours longer if the mother was primipara $(p<0.001)$, and $1.9(0.3-3.5)$ hours shorter if supplementary artificial milk feeds were given. None of the other predictors, i.e., mother's age, gestational age, or induction of labor were significantly associated with infants' SSC with mothers or fathers during any of the first two days after birth.

Conclusion: Future studies are warranted that investigate duration of SSC between late preterm infants and their parents separately and the associations with breastfeeding and other variables of clinical importance. 
1 EARLY SKIN-TO-SKIN CONTACT BETWEEN HEALTHY LATE PRETERM INFANTS

2 AND THEIR PARENTS: AN OBSERVATIONAL COHORT STUDY

3 Short title: Healthy late preterm - Skin-to-skin contact

5 Kerstin H. Nyqvist ${ }^{1, \#}$, Andreas Rosenblad ${ }^{2, \#}$, Helena Volgsten ${ }^{3}$, Eva-Lotta Funkquist ${ }^{1}$, Elisabet

6 Mattsson $^{1,4}$

$8 \quad$ \#Equal contribution

9 1'Department of Women's and Children's Health, Uppsala University, Uppsala, Sweden

10 2Center for Clinical Research Västerås, Uppsala University, Västerås, Sweden

$11{ }^{3}$ Department of Public Health and Caring Sciences, Uppsala University, Uppsala, Sweden

$12{ }^{4}$ Department of Health Care Sciences, Ersta Sköndal Bräcke University College, Stockholm,

13 Sweden

15 Corresponding author:

16 Elisabet Mattsson

17 Ersta Sköndal Bräcke University College

18 Campus Ersta

19 Stigbergsgatan 30

$20 \quad$ Box 11189

21 SE-100 61 Stockholm

22 Sweden

23 E-mail: elisabet.mattsson@esh.se

24 Cell phone: +46732297980 


\section{ABSTRACT}

27 Background: Skin-to-skin contact (SSC) is an important factor to consider in the care of late 28 preterm infants (born between 34 0/7 and 36 6/7 completed weeks of gestation). The literature 29 suggests that SSC between preterm infants and their mothers facilitates breastfeeding. However, more studies are needed to explore potential dose-response effects between SSC and breastfeeding as well as studies that explicitly investigate SSC by fathers among late preterm infants. The aim was to investigate the duration of healthy late preterm infants' SSC with the mother and father, respectively, during the first 48 hours after birth and its associations with breastfeeding (exclusive/partial at discharged), clinical and demographic variables.

Methods: This was an observational cohort study in which parents to healthy late preterm infants, born between 34 5/7 and 36 6/7 completed weeks of gestation, recorded duration of SSC provided by mother and father, respectively. Demographic and clinical variables were retrieved from the medical records and were used as predictors. Multiple linear regression analysis was used to assess the association between the predictors and the outcome, SSC (hours), separately for mothers and fathers.

41 Results: The mean (standard deviation [SD]) time per day spent with SSC with mothers $(\mathrm{n}=64)$ and fathers ( $\mathrm{n}=64)$ was 14.7 (5.6) and 4.4 (3.3) hours during the first day (24 hours) after birth and 9.2 (7.1) and 3.1 (3.3) hours during the second day (24 hours), respectively Regarding SSC with mothers, no variable was significantly associated with SSC during the first day, while the mean $(95 \%$ confidence interval $[\mathrm{CI}])$ time of SSC during the second day was $6.9(1.4-12.4)$ hours

46 shorter for each additional $\mathrm{kg}$ of birthweight $(\mathrm{p}=0.014)$. Concerning SSC with fathers, the mean

$47(95 \% \mathrm{CI})$ time of SSC during the first day was $2.1(0.4-3.7)$ hours longer for infants born at night $48(\mathrm{p}=0.015), 1.7(0.1-3.2)$ hours longer for boys $(\mathrm{p}=0.033), 3.2(1.2-5.2)$ hours longer for infants 
49 born by caesarean section $(\mathrm{p}=0.003)$, and $1.6(0.1-3.1)$ hours longer for infants exclusively

50 breastfed at discharge $(\mathrm{p}=0.040)$. During the second day, the mean $(95 \% \mathrm{CI})$ time of SSC with

51 fathers was $3.0(0.6-5.4)$ hours shorter for each additional $\mathrm{kg}$ of birthweight $(\mathrm{p}=0.014), 2.0(0.5$ -

52 3.6) hours longer for infants born during night time $(p=0.011), 2.9(1.4-4.4)$ hours longer if the

53 mother was primipara $(\mathrm{p}<0.001)$, and $1.9(0.3-3.5)$ hours shorter if supplementary artificial milk

54 feeds were given. None of the other predictors, i.e., mother's age, gestational age, or induction of 55 labor were significantly associated with infants' SSC with mothers or fathers during any of the

56 first two days after birth.

57 Conclusion: Future studies are warranted that investigate duration of SSC between late preterm

58 infants and their parents separately and its associations with breastfeeding and other variables of

59 clinical importance.

60 


\section{INTRODUCTION}

62 Late preterm infants, defined as infants born between 34 0/7 and 36 6/7 completed weeks of

63 gestation (Committee on Obstetric Practice, 2008), are to be considered physiologically

64 immature and should be diligently evaluated, monitored, and followed by health care

65 professionals who are educated to monitor and prevent vulnerabilities associated with

66 prematurity (Raju et al., 2006). Even though late preterm infants are born only a few weeks

67 early, they are at an increased risk for bradycardia, feeding difficulties, hypoglycemia, jaundice,

68 respiratory distress, sepsis, temperature instability, and hospital readmission (Engle et al., 2007;

69 Celik et al., 2013). Lower breastfeeding rates at discharge have been found in late preterms,

70 compared with infants born at term (Ayton et al., 2012).

71 Skin-to-skin contact (SSC), the infant placed naked (with a diaper and with or without a cap) in

72 skin-to-skin contact in a vertical position on the caregiver's bare chest (WHO, 2013), is an

73 important factor to consider in the care of late preterm infants. It has been hypothesised that SSC

74 between preterm infants and their mothers facilitates breastfeeding and breastmilk production,

75 maintains infant body temperature, and enhances infant long-term cognitive development

76 (Britton et al., 2007; Nyqvist et al., 2010; Feldman et al., 2014). Furthermore, evidence supports

77 the use of SSC to promote breastfeeding among healthy infants and the literature indicates that

78 women practicing SSC after cesarean section are more likely to breastfeed up to four months

79 after birth (Moore et al., 2016). Given the health benefits that breast milk confers to preterm

80 infants (American Academy of Pediatrics, 2012) there is a paucity of studies concerning

81 breastfeeding outcomes related to SSC among late preterm infants (Moore et al., 2016). 
83 It is important to distinguish between SSC for healthy infants and kangaroo mother care (KMC).

84 Continuous or intermittent SSC is one of three components of KMC. The other two include 85 exclusive or nearly exclusive breastfeeding and early discharge from hospital (Cattaneo et al., 86 1998; WHO, 2013). The World Health Organization (WHO) guidelines regarding preterm birth 87 outcomes recommend KMC for thermal care for clinically stable newborns weighing $2000 \mathrm{~g}$ or 88 less at birth (WHO, 2015). However, KMC is seldom practiced in its entirety. Consequently, 89 studies regarding $\mathrm{KMC}$ often focus on SSC as the key intervention (Conde-Agudelo \& Días90 Rossello, 2016).

92 So far, research has mainly focused on psychological and physiological effects related to early 93 mother-infant SSC (Conde-Agudelo \& Días-Rossello, 2016; Moore et al., 2016). However, a 94 recent study concludes that no differences regarding physiological and stress responses between 95 SSC provided by fathers versus mothers could be identified among preterm infants (Srinath et 96 al., 2016). Furthermore, twelve studies investigating SSC by fathers and its impact on infant and 97 paternal outcomes have recently been reviewed (Shorey et al., 2016). The authors conclude that 98 father-infant SSC had a positive impact on infants' behavioral response, bio-physiological 99 markers, pain and temperature regulation, as well as paternal distress, interaction behaviour and 100 role attainment.

101

102 To summarise, there is a need for further studies that explicitly investigate SSC by fathers 103 (Shorey et al., 2016). Additionally, the literature regarding SSC highlights that more studies are 104 needed to explore possible dose-response effects between SSC and breastfeeding outcomes 105 (Moore et al., 2016). Against this background, the aim of the present study was to investigate the 
106 duration of healthy late preterm infants' SSC with the mother and father, respectively, during the

107 first 48 hours after birth and its associations with breastfeeding, clinical and demographic 108 variables.

\section{METHODS}

\section{Study design}

112 This was an observational cohort study in which parents to late preterm infants recorded duration 113 of SSC provided by mother and father, respectively.

114 Late preterm infants born between 35-36 completed weeks of gestation were screened for 115 inclusion. Eligibility criteria included: Swedish-speaking parents of a healthy late preterm infant

116 cared for in family rooms at the postnatal ward of Uppsala University Hospital in Uppsala,

117 Sweden. For the purpose of this study, "healthy" means that the infant spent no time in the

118 neonatal intensive care unit, i.e., had no respiratory morbidity, neonatal infection or feeding

119 difficulties that required nasogastric feeds. Neither did the infant require active management for

120 hypothermia (incubator) or support with intravenous fluids due to hypoglycaemia. Exclusion

121 criteria included: multiple births, infants whose mother chose not to breastfeed and infants who 122 needed neonatal intensive care.

123

\section{Study context}

125 The proportion of infants born prematurely has been relatively constant during the past decades

126 in Sweden, that is, nearly 5 percent of all single births. Approximately 4 percent are born

127 between 33-36 completed weeks, whereas one percent is born between 22-32 completed weeks 
128 of gestation (Official Statistics of Sweden, 2014). Approximately 230 late preterm infants are

129 born each year at Uppsala University Hospital in Uppsala, Sweden.

130 At the time of the study, healthy late preterm infants born at $\geq 35$ completed weeks of gestation

131 were routinely cared for at the postnatal wards, i.e., together with term infants. Late preterm

132 infants born $<35$ completed weeks of gestation were routinely cared for at the neonatal intensive

133 care unit and thus, excluded from the present study. Neonatologists directed the infants' medical

134 care plan at the postnatal wards, whereas a midwife working with a nurse assistant (a person who

135 has completed a brief health care training program and provides support services for registered

136 nurses/midwives) provided the midwifery care. The midwife was responsible for providing care

137 for the infant and the mother, including the detection of complications, the accessing of medical

138 care, breastfeeding advice and support, as well as postnatal health counselling and education.

139 The care was family centered, i.e., the majority of fathers/partners stayed together with the

140 mother and the new-born baby in family rooms during the postnatal care period. Siblings had

141 free visiting hours, but were not allowed to stay overnight. Mothers intending to breastfeed were

142 offered individualised support from midwives to facilitate the establishment of lactation and

143 exclusive breastfeeding. According to standard care, the infants were placed SSC on their mother

144 immediately after birth to enable the occurrence of the first breastfeed as soon as possible. If the

145 mother was restricted due to medical reasons from holding the baby after birth, the infant was

146 placed SSC with the father/partner. Health professionals recommended SSC between the infant

147 and the mother/father, i.e., to hold the baby naked (with a diaper and with or without a cap) in

148 the kangaroo position (WHO, 2013) on the caregiver's bare chest during the hospital stay. To

149 manage safe co-sleeping at night, information to parents was based on guidelines from the

150 Swedish National Board of Health and Welfare. The guidelines included placing the infant in a 
151 supine position, making sure that the baby had enough space to move, ensuring that the baby did

152 not get too warm and that the infant's head was not covered. At the time of the study, healthy

153 late preterm infants stayed, on average, for four days at the postnatal ward (Mattsson et al., 154 2015).

155

156 Study sample

157 Ethical approval to conduct the study was obtained from the Regional Ethical Review Board in 158 Uppsala, Sweden (approval number 2010/287).

159 See Figure 1 for numbers of potential participants, participants and reasons for exclusion and 160 attrition.

163 During the inclusion period, between the $15^{\text {th }}$ of November 2010 and the $30^{\text {th }}$ of November 2011 , 164 parents of 86 late preterm infants agreed to participate in the study. However, five infants were 165 excluded as they were referred to the neonatal intensive care unit and parents of 17 infants did 166 not complete the data collection. Thus, parents of $64(61 \%)$ late preterm infants completed the

167 data collection. Forty-three infants were born between 36 0/7 and 36 6/7 completed weeks of 168 gestation, 20 infants between $350 / 7$ and 35 6/7 and one infant was born at $345 / 7$ completed 169 weeks. Due to the real life design of the study, no power calculation was performed.

\section{Data collection}

172 Potential participants i.e., late preterm infants cared for in family rooms at the postnatal wards,

173 were identified through the log book at the hospital's maternity ward. The book includes name of 
174 the ward where the mother/infant were cared for after birth, the mother's name, Swedish

175 identification number, address, date of birth and completed weeks of gestation. Written and oral

176 information about the study was given to parents by the authors EM, ELF, and HV within 24

177 hours after birth at the postnatal ward. Parents who agreed to participate and completed a written

178 informed consent form began completing the diary, one chart per day, commencing from the

179 time they gave their consent, during the infant's stay at hospital. Data from the time of birth to

180 the initiation of study participation were entered retrospectively in the diary by the parents.

181 When the family was discharged from the hospital, the diary was left in a special study mailbox

182 at the postnatal ward. One of the authors (EM) retrieved the study variables from the medical 183 records.

184

185 Data were collected via a parental diary (Blomqvist et al., 2011; Mattsson et al., 2015). The diary

186 consisted of one chart for each day with a timeline (hours and minutes) and columns with fixed

187 options regarding the timing and duration of SSC, breastfeeding and supplementary artificial

188 milk feeds. Parents recorded the duration of each breastfeeding session, supplementary artificial

189 milk feeds and SSC provided by mother/father/others by drawing a line marking the hours and

190 minutes for each variable. The demographic characteristics mother's age (years) and infant's sex

191 (boy/girl), and the clinical variables gestational age (completed weeks and days), infant's

192 birthweight $(\mathrm{kg})$, time of birth (day-time: 07:00-18:59/night-time: 19:00-06:59), parity

193 (primipara/multipara), induction of childbirth (yes/no), mode of delivery (vaginal

194 delivery/caesarean section), supplemental feeding (given/not given), and breastfeeding at

195 discharge (partial/exclusive), were used as predictors. Other clinical variables of importance,

196 such as signs of fetal asphyxia according to fetal heart rate monitoring $(n=2)$, vacuum extraction 
$197(n=2)$, manual extraction of placenta $(n=1)$, large perineal tears $(n=1)$, and postpartum bleeding

$198>1000 \mathrm{ml}(\mathrm{n}=1)$ were assessed but were not used in the analyses due to too few observations to

199 perform any relevant statistical analyses. Demographic and clinical variables were chosen on the

200 basis of the available literature at the time of the study (Britton, et al., 2007; Erlandsson et al.,

201 2007; Raju, et al., 2006; Walker, 2008) and clinical experiences of the members in the research

202 group. Breastfeeding at discharge was defined according to the World Health Organization

203 (WHO) definition of exclusive breastfeeding, that is, the infant received only breast milk without

204 any additional food or drink (not even water) at discharge.

205

206 Data regarding SSC during the first 48 hours after birth are presented in the present study, 207 whereas data regarding supplementary artificial milk feeds related to breastfeeding and 208 associated clinical parameters have been presented elsewhere (Mattsson et al., 2015).

\section{Statistical analyses}

211 The outcome of interest in the present study was the duration of the infant's SSC with the mother

212 and father during the first and second days (24 hours), respectively, after birth and the

213 associations with breastfeeding, clinical and demographic variables.

214 Sample characteristics are described by frequencies and percentages, $\mathrm{n}(\%)$, for categorical

215 variables and by means and standard deviations (SD), supplemented by median and range, for

216 continuous variables. Linear regression analyses were used for assessing the associations

217 between the predictors and the outcome, separately for mothers and fathers. Three kinds of

218 regression models were used: (i.) The unadjusted model, using each predictor in separate

219 regression models, (ii.) The full model, including all predictors simultaneously in the same 
220 regression model, and (iii.) The trimmed model, using a backward elimination approach starting

221 with the full model and step-by-step deletion of the variable with the highest p-value, re-

222 estimating the model and deleting the variable which now had the highest $\mathrm{p}$-value, and so on,

223 with the process continuing until only variables with p-values $<0.20$ remained in the model

224 (Newbold, 1995). No adjustments were made for multiple comparisons. IBM SPSS Statistics

225 22/23/24 (IBM Corp., Armonk, NY) was used for statistical analyses. Two-sided p-values $<0.05$

226 were considered statistically significant.

227

228

RESULTS

229 Parents' of 64 healthy late preterm infants completed the data collection about SSC.

230 Characteristics of the study sample and the care provided are given in Table 1.

231

Insert Table 1 about here

232

233 The mothers' median (range) age was 30.5 (19-40) years. Thirteen mothers (20.3\%) gave birth

234 by caesarean section, of which two (3.1\%) were elective. The median (range) of infants' 235 gestational age was 36 2/7 (34 5/7 - 36 6/7) weeks. No infant had an Apgar score below 7 points 236 at 5 minutes after birth.

238 During the first day after birth, the infants' median time spent SSC with mothers (n=64) was 23914.8 hours (range 0.0-24.0) and 4.3 hours (range 0.0-14.0) with fathers. The second day the 240 corresponding figures were 9.0 hours (range 0.0-24.0) SSC with mothers and 2.5 hours (range $2410.0-13.0)$ SSC with fathers. 
243 The associations between the demographic and clinical variables, on the one hand, and the 244 infants SSC with mothers and fathers during the first and second 24 hours after birth on the other 245 hand, are presented in Table 2 and Table 3, respectively.

Insert Table 2 and Table 3 about here

247

248 None of the demographic or clinical variables were significantly associated with SSC with 249 mothers during the first day. However, the infant's birthweight was strongly associated with SSC 250 with mothers during the second day, with a mean (95\% confidence interval [CI]) of 6.9 (1.4-

251 12.4) hours shorter SSC for each additional $\mathrm{kg}$ of birthweight for the trimmed model $(\mathrm{p}=0.014)$, 252 i.e., infants with lower birthweights had more SSC than infants with higher birthweights (Table 253 2).

254 Among fathers, time of birth, infant's gender, mode of delivery, and exclusive breastfeeding at 255 discharge were all significantly associated with SSC during the first day in the trimmed model, 256 with a mean $(95 \% \mathrm{CI})$ of $2.1(0.4-3.7)$ hours longer SSC for infants born at night $(\mathrm{p}=0.015), 1.7$ 257 (0.1-3.2) hours longer SSC if the infant was a boy ( $\mathrm{p}=0.033), 3.2(1.2-5.2)$ hours longer SSC if 258 the infant was born by caesarean section $(\mathrm{p}=0.003)$, and $1.6(0.1-3.1)$ hours longer SSC if the 259 infant was exclusively breastfed at discharge $(\mathrm{p}=0.040)$. During the second day, the infant's 260 birthweight, time point of birth, parity, and if supplemental feeding were given, were all 261 significantly associated with SSC with the father in the trimmed model, with a mean $(95 \% \mathrm{CI})$ of $2623.0(0.6-5.4)$ hours shorter SSC for each additional $\mathrm{kg}$ of birthweight $(\mathrm{p}=0.014), 2.0(0.5-3.6)$ 263 hours longer SSC for infants born at night $(\mathrm{p}=0.011), 2.9$ (1.4-4.4) hours longer SSC if the 264 mother was primipara $(\mathrm{p}<0.001)$, and $1.9(0.3-3.5)$ hours shorter SSC for infants given 265 supplementary artificial milk feeds $(\mathrm{p}=0.024)$ (Table 3$)$. 
267 None of the following variables were associated with infants' SSC with mothers (Table 2) or

268 fathers (Table 3) during any of the first two days after birth: mother's age, gestational age, or 269 induction of childbirth.

270

\section{DISCUSSION}

272 This is one of the first studies that explicitly investigate duration of SSC between healthy late

273 preterm infants and their mothers and fathers separately and its associations with breastfeeding,

274 clinical and demographic variables.

275

276 Breastfeeding at discharge was not associated with the extent of infants' SSC with mothers

277 during any of the first two days after birth. However, all mothers in our study were breastfeeding 278 to some extent at hospital discharge, $47 \%$ exclusively. Research regarding dose-response effect 279 between duration of SSC and breastfeeding is ambiguous (Bramson et al., 2010; Moore et al., 280 2016). In contrast to our results, which present the dose-response association during a 24-hour 281 day, Bramson et al. (2010) found a clear dose-response association between mother-infant 282 duration of SSC for the first 3 hours following birth and exclusive breastfeeding during 283 hospitalisation. Moore et al. (2016), on the other hand, demonstrated in their review no 284 differences between less versus more than 60 minutes of SSC in the first 24 hours after birth and 285 breastfeeding one to four months post birth. However, it must be acknowledged that differences 286 in breastfeeding outcomes can also be explained by other differences in mothers' experiences in

287 hospital, such as feeding policies (Mattsson, et al., 2015). To reach firm conclusions regarding 288 duration of SSC after birth and its associations with both short- and long-term breastfeeding, 
289 further studies are needed, in which data are collected about the total duration of SSC between 290 mothers and infants after birth, and about all other relevant hospital practices related to the 291 outcome variables.

292

293 Among fathers, mode of delivery was significantly associated with SSC during the first day, with

294 longer SSC if the infant was born by caesarean section. Following caesarean birth, early SSC 295 between mother and her newborn infant may be limited due to practical and medical safety 296 reasons for both infant and woman (Moore et al., 2016). Data regarding infants' outcomes when 297 cared for skin-to-skin with their father versus next to the father in a cot after caesarean birth have 298 been evaluated (Erlandsson et al., 2007). The authors conclude that infants in the SCC group 299 cried less and that their pre-feeding behaviour was promoted compared with infants in the cot 300 group. The latter may be attributed to our result showing that a mean duration of 4.4 hours/day of

301 SSC between infant-father the first 24 hours following birth was associated with exclusive 302 breastfeeding at discharge. Thus, it could be hypothesised that other caregivers than the mother 303 can facilitate the development of the late preterm infant's early feeding cues.

305 More SSC during the second day for infants with lower birthweights was the only variable that 306 was significant for both mothers and fathers. These results indicate that recommendations for 307 international guidelines (Nyqvist et al., 2010) regarding SSC between low birthweight infants 308 and their parents have, at least partially, been implemented in clinical practices in Sweden. In our 309 study, the mean \pm standard deviation total time spent with SSC with mothers the second day was $3109.2 \pm 7.1$ hours, whereas the corresponding figures for fathers were 3.1 \pm 3.3 hours. Although the 311 reported time for SSC between infants and parents in this study is higher compared to reports 
312 from other settings in Scandinavia (Olsson et al., 2012), continuous SSC still remains an

313 underused method of care for healthy late preterm infants in Sweden. This is underscored in our

314 study as gestational age was not associated with infants' SSC with mothers or fathers during any

315 of the first two days after birth.

316

317 It has been concluded that parents' satisfaction with support for SSC in postnatal care is

318 associated with a larger extent of SSC during the first days after birth (Calais et al., 2010). Thus,

319 nurses and midwives have a unique position to influence the use of SSC in clinical practice.

320 However, nurses have expressed conflicting perceptions about SSC as they acknowledged its

321 advantages for both infant and parents, but also questioned if the method is safe for the infants

322 (Blomqvist et al., 2013; Mörelius \& Anderson, 2015). In our study, no adverse event related to

323 SSC was documented. Sudden unexpected postnatal collapse (SUPC) is a rare and dreaded

324 complication that occurs among presumably healthy newborn infants within their first day of life.

325 SUPC includes any condition resulting in temporary or permanent cessation of breathing or

326 cardiorespiratory failure (Pejovic \& Herlenius, 2013). Identified risk factors include prone

327 position during SSC, unsupervised breastfeeding during the first two hours after birth,

328 primiparity, and parents distracted by mobile phones (Pejovic \& Herlenius, 2013). Consequently,

329 specific policies and guidelines that address infants' safety during SSC are needed (Chia et al.,

330 2006, Pejovic \& Herlenius, 2013). The implementation of such guidelines may in turn ease

331 nurses' concerns regarding postnatal surveillance for late preterm infants receiving SSC and thus

332 promote further use of the method. Inadequate staffing and education of staff on SSC has also

333 been described as barriers to optimal implementation (Koopman et al., 2016) as well as visitors

334 in the room during mothers' hospital stay (Calais et al., 2010; Ferrarello \& Hatfield, 2014). 
336 In the present study, SSC between the late preterm infant and the mother/father were measured

337 and analysed separately. We can conclude that fathers provided SSC less than half the amount of

338 time than mothers did and furthermore, fathers provided less SSC if supplemental methods of

339 feeding were administered. Differences in gender roles may contribute to these findings, as

340 mothers tend to take more responsibility for childcare and bond more strongly with a sick child

341 compared to fathers (Coffey, 2006). Although the infants in our study were defined as "healthy",

342 it is possible that this explanation also applies to vulnerable newborns, i.e., late preterm infants.

344 Parity was associated with SSC with the father the second day after birth. Fathers provided 2.9

345 hours longer SSC if the mother was primipara, compared to if the mother was multipara. It could

346 be speculated that fathers were the primary caregiver to siblings during mothers' and late preterm

347 infants' hospital stay. This is underscored by the fact that siblings were not allowed to stay

348 overnight at the hospital. The $20^{\text {th }}$ century has been characterised by social trends that have

349 fundamentally changed the social context in which children develop, namely women's increased

350 labor force participation and subsequently increased involvement of fathers (Cabrera et al.,

351 2000). In Sweden, these trends are further underscored by the fact that 25 percent of the fathers

352 share their parental leave with the mother, which, according to Swedish legislation, can be

353 divided equally between the parents (Statistics Sweden, 2016). Although Sweden differs from

354 other western countries with regard to parental leave, it is reasonable to assume that fathers'

355 contribution to infant care will continue to increase in western societies during the present

356 century. As a consequence, gender perspective needs to be implemented in clinical practice and

357 research in pediatric care. 
359 Infant's gender was associated with longer SSC among fathers for the first 24 hours after birth,

360 with 1.9 hours longer SSC if the infant was a boy. This result is hard to interpret as studies

361 investigating differences with regard to SSC between the four dyads of mother-daughter, mother-

362 son, father-daughter and father-son is scarce. However, Velandia et al. (2012) conclude that

363 mothers used more touching behaviour towards their newborn infant than fathers. Furthermore,

364 mothers touched girls less than boys and fathers directed less speech towards girls than boys.

365 There are psychoanalytic (Washburn, 1994) and gender theories (Thompson \& Walker, 1989)

366 suggesting that relationships within the family, e.g., the content or styles of interactions, are

367 organised on the basis of gender. Others, on the other hand, argue that gender is only one of

368 many factors influencing parent-child relationships (Volling \& Belsky, 1991; Russell \& Saebel,

369 1997). Our result raises questions of whether gender alone is important enough to create distinct

370 relationships from birth between fathers and sons. However, further studies are needed to

371 confirm whether an infant's gender influences duration of SSC with mothers and fathers,

372 respectively among late preterm infants.

373

374 Our study had some limitations. An important factor to consider is that the sample included

375 healthy late preterm infants born between 34 5/7 and 36 6/7 weeks of completed gestation.

376 Consequently, the generalizability to late preterm infants as a group is limited. The sample size

377 was too small to detect the extent of use of SSC when mothers suffered relatively rare birth

378 complications, e.g., vacuum extraction, large perinatal tears and postpartum bleeding $>1000 \mathrm{ml}$,

379 etc. National or even international research co-operations are needed to explore how to

380 implement SSC among late preterm infants in these situations. Furthermore, our study did not 
381 include data concerning other comorbidities that may affect breastfeeding, for example,

382 pregnancy-induced hypertension and diabetes. Additionally, we did not collect any data

383 regarding ethnicity. The latter is an important factor as socio-cultural context and norms

384 influence SSC uptake (Chan et al., 2016) as well as breastfeeding rates and practices (Jones et

385 al., 2015).

386 The response rate in the present study was $61 \%$. However, parents of 17 infants (21\%) did not

387 complete the data collection about SSC. It could be speculated that these parents found the

388 documentation in the diary complex and time-consuming. Another aspect to consider is that the

389 data regarding SSC were based only on self-reports and that data from birth to study initiation

390 was reported by the parents retrospectively. Our choice of data collection in the present study,

391 i.e., the diary, was based on a previous study concluding that parents are able to document

392 variables related to SSC of their infant in a complete and reliable manner (Blomqvist et al.,

393 2011). Finally, the explained variation in the model, as given by $\mathrm{R}^{2}$, was quite high, especially

394 for fathers, with values of $33.4 \%$ for day 1 and $39.0 \%$ for day 2 . However, due to the small

395 sample size used, the results need to be interpreted with some caution.

397 CONCLUSIONS

398 The present study raises questions regarding dose-response effects between duration of SSC and 399 breastfeeding. Exclusive breastfeeding at discharge was significantly associated with infants' 400 duration of SSC with fathers during the first day after birth, whereas no associations were found 401 with mothers. Future studies are warranted that investigate duration of SSC between late preterm 402 infants and their parents separately and its associations with breastfeeding. Taken together, a 403 gender perspective needs to be implemented in paediatric research as the inclusion of mothers 
404 alone or parents as a couple may hinder firm conclusions regarding variables of importance for 405 the infant's care.

406 
407

408

409

410

411

412

413

414

415

416

417

418

419

420

421

422

423

424

425

426

427

428

429

430

431

432

433

434

435

436

437

438

439

440

441

442

443

444

445

446

447

448

449

450

451

\section{REFERENCES}

American Academy of Pediatrics. 2012. Section on Breastfeeding: Breastfeeding and the use of human milk. Pediatrics 129:e827-41. DOI: 10.1542/peds.2011-3552.

Ayton J, Hansen E, Quinn S, Nelson M. 2012. Factors associated with initiation and exclusive breastfeeding at hospital discharge: late preterm compared to 37 week gestation mother and infant cohort. International Breastfeeding Journal 26;7(1):16. DOI: 10.1186/1746-4358-7-16.

Blomqvist Y.T, Rubertsson C, Nyqvist K.H. 2011. Parent-infant skin-to-skin contact; How do parent records compared to nurse records? Acta Paediatrica 100(5):773-5. DOI:10.1111/j.16512227.2011.02160.x.

Blomqvist Y.T, Frölund L, Rubertsson C, Nyqvist K.H. 2013. Provision of Kangaroo Mother Care: supportive factors and barriers perceived by parents. Scandinavian Journal of Caring Sciences 27(2):345-53. DOI: 10.1111/j.1471-6712.2012.01040.x.

Bramson L, Lee J.W, More E, Montgomery S, Neish C, Bahjri K, Melcher CL. 2010. Effect of early skin-to-skin mother-infant contact during the first 3 hours following birth on exclusive breastfeeding during the maternity hospital stay. Journal of Human Lactation 26(2):130-7. DOI: $10.1177 / 0890334409355779$.

Britton C, McCormick F.M, Renfrew M.J, Wade A, King S.E. 2007. Support for breastfeeding mothers. The Cochrane Database of Systematic Reviews 24(1):CD001141. DOI: 10.1002/14651858.CD001141.pub3.

Calais E, Dalbye R, Nyqvist K.H, Berg M. 2010. Skin-to-skin contact of fullterm infants: an explorative study of promoting and hindering factors in two Nordic childbirth settings. Acta Paediatrica 99:1080-90. Doi: 10.1111/j.1651-2227.2010.01742.x.

Carbera NJ, Tamis-LeMond, CS, Bradley RH, Hofferth S, Lamb ME. 2000. Fatherhood in the twenty-first century. Child Development 71(1):127-36.

Cattaneo A, Davanzo R, Uxa F, Tamburlini G. 1998. Recommendations for the implementation of Kangaroo Mother Care for low birthweight infants. International Network on Kangaroo Mother Care. Acta Paediatrica 87(4):440-5.

Celik I.H, Demirel G, Canpolat F.E, Dilmen U. 2013. A common problem for neonatal intensive care units: late preterm infants, a prospective study with term controls in a large perinatal center. Journal of Maternal-Fetal \& Neonatal Medicine 26(5):459-62. DOI: 10.3109/14767058.2012.735994.

Chan GJ, Labar AS, Wall S, Atun R. 2016. Kangeroo mother care: a systematic review of barriers and enablers. Bulletin of the World Health Organization 94(2):130-41. DOI:

10.2471/BLT.15.157818. 
452

453

454

455

456

457

458

459

460

461

462

463

464

465

466

467

468

469

470

471

472

473

474

475

476

477

478

479

480

481

482

483

484

485

486

487

488

489

490

491

492

493

494

495

496

497
Chia P, Sellick K, Gan S. 2006. The attitudes and practices of neonatal nurses in the use of kangaroo care. Australian Journal of Advanced Nursing 23(4):20-7.

Coffey JS. 2006. Parenting a child with chronic illness: a metasynthesis. Journal of Pediatric Nursing 32:51-9.

Committee on Obstetric Practice. 2008. ACOG committee opinion No. 404 April 2008. Latepreterm infants. Obstetrics \& Gynecology 111(4):1029-32 pmid:18378769. DOI: 10.1097/AOG.0b013e31817327d0.

Conde-Agudelo A. \& Días-Rossello JL. 2016. Kangaroo mother care to reduce morbidity and mortality in low birthweight infants. The Cochrane Database of Systematic Reviews 23(8):CD002771. DOI:10.1002/14651858.CD002771.pub4.

Engle WA, Tomashek KM, Wallman C.; Committee on Fetus and Newborm, American Academy of Pediatrics. 2007. "Late preterm" infants: a population at risk. Pediatrics 120(6):1390-401. DOI: 10.1542/peds.2007-2952.

Erlandsson K, Dsilna A, Fagerberg I, Christensson K. 2007. Skin-to-skin care with the father after cesarean birth and its effect on newborn crying and prefeeding behavior. Birth 34(2):10514. DOI: $10.1111 / \mathrm{j} .1523-536 X .2007 .00162 . x$.

Feldman R, Rosenthal Z, Eidelman A.I. 2014. Maternal-preterm skin-to-skin contact enhances child physiologic organization and cognitive control across the first 10 years of life. Biological Psychiatry 75(1):56-64. DOI: 10.1016/j.biopsych.2013.08.012.

Ferrarello D. \& Hatfield L. 2014. Barriers to skin-to-skin care during postpartum stay. MCN. The American Journal of Maternal Child Nursing 39(1):56-61. DOI:

10.1097/01.NMC.0000437464.31628.3.d.

Jones KM, Power ML, Queenan JT, Schulkin J. 2015. Racial and ethnic disparities in breastfeeding. Breastfeeding Medicine 10(4):186-96. DOI: 10.1089/bfm.2014.0152.

Koopman I, Callaghan-Koru JA, Alaofin O, Argani CH, Farzin A. 2016. Early skin-to-skin contact for healthy full-term infants after vaginal and caesarean delivery: a qualitative study on clinician perspectives. Journal of Clinical Nursing 25(9-10):1367-76. DOI: 10.1111/jocn.13227.

\begin{tabular}{|l|l|}
\hline 1 &
\end{tabular}

Mattsson E, Funkquist E-L, Wickström M, Nyqvist K.H, Volgsten H. 2015. Healthy late preterm infants and supplementary artificial milk feeds: Effects on breast feeding and associated clinical parameters. Midwifery 31(4):426-31. DOI:10.1016/j.midw.2014.12.004.

Moore ER, Bergman N, Andersson GC, Medley N. 2016. Early skin-to-skin contact for mothers and their healthy newborn infants. The Cochrane Database of Systematic Reviews 25(11):CD003519. DOI: 10.1002/14651858.CD003519.pub4. 
498

499

500

501

502

503

504

505

506

507

508

509

510

511

512

513

514

515

516

517

518

519

520

521

522

523

524

525

526

527

528

529

530

531

532

533

534

535

536

537

538

539

540

541

542

Mörelius E. \& Anderson GC. 2015. Neonatal nurses' beliefs about almost continuous parentinfant skin-to-skin contact in neonatal intensive care. Journal of Clinical Nursing 24(1718):2620-7. DOI: 10.1111 jocn. 12877.

Newbold P. Statistics for Business \& Economics, $4^{\text {th }}$ ed. Prentice-Hall: Upper Saddle River, NJ.

Nyqvist K.H, Anderson G.C, Bergman N, Cattaneo A, Charpak N, Davanzo R, Ewald U, Ibe O, Ludington-Hoe S, Mendoza S, Pallás-Allonso C, Ruiz Peláez JG, Sizun J, Widström AM. 2010. Towards universal Kangaroo Mother Care: recommendations and report from the First European Conference and Seventh International Workshop on Kangaroo Mother Care. Acta Paediatrica 99(6):820-6. DOI: 10.1111/j.1651-2227.2010.01787.x.

Official Statistics of Sweden. Statistics - Health and Medical care. 2014. Pregnancies, Deliveries and Newborn Infants. The Swedish Medical Birth Register 1973-2013. Assisted Reproduction, treatment 1991-2012. Available from:

https://www.socialstyrelsen.se/Lists/Artikelkatalog/Attachments/19627/2014-12-19.pdf

Olsson E, Andersen R.D, Axelin A, Jonsdottir R.B, Maastrup R, Eriksson M. 2012. Skin-to-skin care in neonatal intensive care units in the Nordic countries: A survey of attitudes and practices. Acta Paediatrica 101(11):1140-6. DOI: 10.1111/j.1651-2227.2012.02802.x.

Pejovic N.J. \& Herlenius E. 2013. Unexpected collapse of healthy newborn infants: risk factors, supervision and hypothermia treatment. Acta Paediatrica 102(7):680-8. DOI:

10.1111.apa.12244.

Raju T.N, Higgins R.D, Stark A.R, Leveno K.J. 2006. Optimizing care and outcome for late preterm (near-term) infants: a summary of the workshop sponsored by the National Institute of Child Health and Human Development. Pediatrics 118:1207-14. DOI: 10.1542/peds.2006-0018. 1

Russell A. \& Saebel J. 1997. Mother-Son, Mother-Daughter, Father-Son, and Father-Daughter: Are they distinct relationships? Developmental Review 17:111-47.

Shorey S, He HG, Morelius E. 2016. Skin-to-skin contact by fathers and the impact on infant and paternal outcomes: an integrative review. Midwifery 40:207-17. DOI:

10.1016/j.midw.2016.07.007.

Srinath BK, Shah J, Kumar P, Shah PS. 2016. Kangaroo care by fathers and mothers: comparison of physiological and stress responses in preterm infants. Journal of Perinatology 36(5):404-4. DOI: 10.1038/jp.2015.196.

Statistics Sweden. 2016. Women and Men in Sweden 2014 Fact and Figures. SCB-tryck, Örebro: Sweden. Available from:

http://www.scb.se/Statistik/_Publikationer/LE0201_2013B14_BR_X10BR1401ENG.pdf 
543 Thompson L. \& Walker A.J. 1989. Gender in families: Women and men in marriage, work, and 544 parenthood. Journal of Marriage and the Family 51:845-71.

545

546 Velandia M, Uvnäs-Moberg K, Nissen E. 2012. Sex differences in newborn interaction with

547 mother or father during skin-to-skin contact after caesarean section. Acta Paediatrica

548 101(4):360-7. DOI: 10.1111/j.1651-2227.2011.02523.x.

549

550 Volling B.L. \& Belsky J. 1991. Multiple determinants of father involvement during infancy in

551 dual-earner and single earner families. Journal of Marriage and the Family 53:461-74.

552

553 Walker M. 2008. Breastfeeding the late preterm infant. Journal of Obstetric, Gynecologic, \& 554 Neonatal Nursing 37:692-701. DOI: 10.1111/j.1552-6909.2008.00293.x.

555

556 Washburn M. 1994. Reflections on a psychoanalytic theory of gender difference. Journal of

557 American Academy of Psychoanalysis 22:1-28.

558

559 WHO. 2013. Kangaroo Mother Care: a practical guide. Geneva. Available from:

560 http://apps.who.int/iris/bitstream/10665/42587/1/9241590351.pdf

561

562 WHO. 2015. WHO recommendations on interventions to improve preterm birth outcomes.

563 Available from:

564 http://apps.who.int/iris/bitstream/10665/183037/1/9789241508988_eng.pdf?ua=1 


\section{Table $\mathbf{1}$ (on next page)}

Duration of SSC with mothers $(n=64)$ and fathers $(n=64)$ and description of demographic and clinical variables. 
1

\begin{tabular}{|c|c|}
\hline Variables & $\begin{array}{l}\text { Mean } \pm \mathrm{SD} / \\
\text { Proportions }\end{array}$ \\
\hline Skin-to-skin contact & \\
\hline \multicolumn{2}{|c|}{ Duration the first day after birth ( 24 hours) } \\
\hline - $\quad$ Mothers (hours) & $14.7 \pm 5.6$ \\
\hline - $\quad$ Fathers (hours) & $4.4 \pm 3.3$ \\
\hline \multicolumn{2}{|c|}{ Duration the second day after birth ( 24 hours) } \\
\hline - $\quad$ Mothers (hours) & $9.2 \pm 7.1$ \\
\hline - $\quad$ Fathers (hours) & $3.1 \pm 3.3$ \\
\hline \multicolumn{2}{|l|}{ Demographic variables } \\
\hline Mother's age (years) & $30.3 \pm 5.0$ \\
\hline \multicolumn{2}{|l|}{ Infant's gender } \\
\hline - $\quad$ Girl & $48.4 \%$ \\
\hline - $\quad$ Boy & $51.6 \%$ \\
\hline \multicolumn{2}{|l|}{ Clinical variables } \\
\hline \multicolumn{2}{|l|}{ Parity } \\
\hline - $\quad$ Primipara & $45.3 \%$ \\
\hline - $\quad$ Multipara & $54.7 \%$ \\
\hline \multicolumn{2}{|l|}{ Induction of childbirth } \\
\hline - $\quad$ Yes & $20.3 \%$ \\
\hline$-\quad$ No & $79.7 \%$ \\
\hline \multicolumn{2}{|l|}{ Mode of delivery } \\
\hline - $\quad$ Vaginal delivery & $79.7 \%$ \\
\hline - Caesarean section & $20.3 \%$ \\
\hline \multicolumn{2}{|l|}{ Time point of birth (24-hour clock) } \\
\hline - $\quad$ Day-time (07:00-18:59) & $53.1 \%$ \\
\hline
\end{tabular}




\begin{tabular}{|c|l|}
\hline$-\quad$ Night-time (19:00-06:59) & $46.9 \%$ \\
\hline Gestational age (weeks) & $36.2 \pm 0.6$ \\
\hline$-\quad 345 / 7-356 / 7$ & $32.8 \%$ \\
\hline$-\quad 360 / 7-366 / 7$ & $67.2 \%$ \\
\hline Infant's birthweight (kg) & $2.9 \pm 0.3$ \\
\hline Supplementary artificial milk feeds & $65.6 \%$ \\
\hline - Given & $34.4 \%$ \\
\hline - Not given & \\
\hline Breastfeeding at discharge & $53.1 \%$ \\
\hline Partial & $46.9 \%$ \\
\hline Exclusive & \\
\hline
\end{tabular}

2 Abbreviation: SD, standard deviation

$3{ }^{1}$ The infant received only breast milk without any additional food or drink, not even water, at discharge. 


\section{Table 2 (on next page)}

Results from multiple linear regression for associations with infants' SSC with mothers the first and second day (24 hours) after birth, respectively. Significant p-values are printed in bold. 


\begin{tabular}{|c|c|c|c|c|c|c|c|}
\hline & & Unadjusted & & Full model ${ }^{\mathrm{a}}$ & & Trimmed model $^{\mathrm{b}}$ & \\
\hline Day & Variable & $\beta(95 \% \mathrm{CI})$ & $\mathrm{P}$ & $\beta(95 \% \mathrm{CI})$ & $\mathrm{P}$ & $\beta(95 \% \mathrm{CI})$ & $\mathrm{P}$ \\
\hline \multirow{10}{*}{ First } & Mother's age (years) & $0.019(-0.264: 0.302)$ & 0.893 & $0.036(-0.299 ; 0.371)$ & 0.831 & $-^{c}$ & \\
\hline & Boy & $-2.617(-5.352 ; 0.119)$ & 0.061 & $-2.881(-5.936 ; 0.174)$ & 0.064 & $-2.658(-5.413 ; 0.098)$ & 0.058 \\
\hline & Primipara & $-1.641(-4.437 ; 1.154)$ & 0.245 & $-1.146(-4.286 ; 1.994)$ & 0.467 & $-^{c}$ & \\
\hline & Induction of childbirth & $1.126(-2.360 ; 4.611)$ & 0.521 & $-0.394(-4.143 ; 3.356)$ & 0.834 & $-^{c}$ & \\
\hline & Caesarean section & $-2.084(-5.541 ; 1.373)$ & 0.233 & $-3.250(-7.322 ; 0.821)$ & 0.115 & $-2.229(-5.590 ; 1.133)$ & 0.190 \\
\hline & Night time birth & $-0.030(-2.849 ; 2.789)$ & 0.983 & $-0.987(-4.146 ; 2.173)$ & 0.534 & $\iota^{c}$ & \\
\hline & Gestational age (weeks) & $-0.396(-2.928: 2.136)$ & 0.756 & $-0.535(-3.599 ; 2.530)$ & 0.728 & $-^{c}$ & \\
\hline & Infant's birth weight (kg) & $-0.692(-5.136 ; 3.752)$ & 0.757 & $-1.789(-6.798 ; 3.221)$ & 0.477 & $-^{c}$ & \\
\hline & Supplementary artificial milk feeds given & $-1.549(-4.485 ; 1.387)$ & 0.296 & $-2.164(-6.320 ; 1.992)$ & 0.301 & $-2.624(-6.123 ; 0.875)$ & 0.139 \\
\hline & Exclusive breastfeeding at discharge & $-1.191(-3.994 ; 1.612)$ & 0.399 & $-2.601(-6.262 ; 1.060)$ & 0.160 & $-3.186(-6.458 ; 0.087)$ & 0.056 \\
\hline \multirow[t]{10}{*}{ Second } & Mother's age (years) & $-0.164(-0.523 ; 0.196)$ & 0.366 & $-0.245(-0.662 ; 0.173)$ & 0.245 & $\iota^{c}$ & \\
\hline & Boy & $-3.823(-7.286 ;-0.360)$ & 0.031 & $-2.947(-6.756 ; 0.862)$ & 0.127 & $-3.276(-6.757 ; 0.206)$ & 0.065 \\
\hline & Primipara & $-0.972(-4.574 ; 2.630)$ & 0.592 & $-1.573(-5.488 ; 2.342)$ & 0.424 & $-c$ & \\
\hline & Induction of childbirth & $0.087(-4.380 ; 4.554)$ & 0.969 & $-2.884(-7.559 ; 1.791)$ & 0.221 & $\iota^{c}$ & \\
\hline & Caesarean section & $-0.275(-4.742 ; 4.192)$ & 0.902 & $-0.850(-5.926 ; 4.227)$ & 0.738 & $-^{c}$ & \\
\hline & Night time birth & $-1.421(-5.005 ; 2.162)$ & 0.431 & $-1.356(-5.295 ; 2.583)$ & 0.493 & $-^{c}$ & \\
\hline & Gestational age (weeks) & $-0.382(-3.618 ; 2.853)$ & 0.814 & $-1.222(-5.042 ; 2.599)$ & 0.524 & $-c$ & \\
\hline & Infant's birth weight $(\mathrm{kg})$ & $-6.321(-11.888 ;-0.755)$ & 0.027 & $-8.482(-14.727 ;-2.236)$ & 0.009 & $-6.941(-12.444 ;-1.438)$ & 0.014 \\
\hline & Supplementary artificial milk feeds given & $-2.425(-6.159 ; 1.309)$ & 0.199 & $-4.097(-9.279 ; 1.085)$ & 0.119 & $-2.530(-6.262 ; 1.202)$ & 0.180 \\
\hline & Exclusive breastfeeding at discharge & $0.555(-3.044 ; 4.154)$ & 0.759 & $-2.376(-6.940 ; 2.189)$ & 0.301 & $-^{c}$ & \\
\hline \multicolumn{8}{|c|}{${ }^{a}$ First day: $\mathrm{R}^{2}=0.171 ;$ second day $\mathrm{R}^{2}=0.241$} \\
\hline \multicolumn{8}{|c|}{${ }^{\mathrm{b}}$ First day: $\mathrm{R}^{2}=0.142 ;$ second day $\mathrm{R}^{2}=0.177$} \\
\hline & & & & & & & \\
\hline
\end{tabular}




\section{Table 3 (on next page)}

Results from multiple linear regression for associations with infants' SSC with fathers the first and second day (24 hours) after birth, respectively. Significant p-values are printed in bold. 


\begin{tabular}{|c|c|c|c|c|c|c|c|}
\hline Day & Variable & $\begin{array}{l}\text { Unadjusted } \\
\beta(95 \% \mathrm{CI})\end{array}$ & $\mathrm{P}$ & $\begin{array}{l}\text { Full model }{ }^{\mathrm{a}} \\
\beta(95 \% \mathrm{CI})\end{array}$ & $\mathrm{P}$ & $\begin{array}{l}\text { Trimmed model }{ }^{\mathrm{b}} \\
\beta(95 \% \mathrm{CI})\end{array}$ & $\mathrm{P}$ \\
\hline \multirow[t]{10}{*}{ First } & Mother's age (years) & $0.001(-0.165 ; 0.167)$ & 0.992 & $-0.050(-0.230 ; 0.131)$ & 0.583 & $\iota^{c}$ & \\
\hline & Boy & $1.512(-0.096 ; 3.121)$ & 0.065 & $1.907(0.262 ; 3.551)$ & 0.024 & $1.678(0.137 ; 3.220)$ & 0.033 \\
\hline & Primipara & $1.701(0.097 ; 3.304)$ & 0.038 & $1.363(-0.327 ; 3.053)$ & 0.112 & $1.297(-0.316 ; 2.910)$ & 0.113 \\
\hline & Induction of childbirth & $0.546(-1.503 ; 2.596)$ & 0.596 & $1.214(-0.804 ; 3.233)$ & 0.233 & $1.278(-0.647 ; 3.203)$ & 0.189 \\
\hline & Caesarean section & $1.753(-0.253 ; 3.759)$ & 0.086 & $3.273(1.081 ; 5.464)$ & 0.004 & $3.177(1.153 ; 5.202)$ & 0.003 \\
\hline & Night time birth & $0.676(-0.971 ; 2.323)$ & 0.415 & $2.036(0.336 ; 3.737)$ & 0.020 & $2.051(0.413 ; 3.689)$ & 0.015 \\
\hline & Gestational age (weeks) & $0.169(-1.319 ; 1.657)$ & 0.821 & $0.508(-1.141 ; 2.158)$ & 0.539 & $-c$ & \\
\hline & Infant's birth weight $(\mathrm{kg})$ & $-2.672(-5.255 ;-0.089)$ & 0.043 & $-2.390(-5.086 ; 0.306)$ & 0.081 & $-1.956(-4.451 ; 0.539)$ & 0.122 \\
\hline & Supplementary artificial milk feeds given & $0.182(-1.557 ; 1.922)$ & 0.835 & $-0.419(-2.656 ; 1.818)$ & 0.709 & $\iota^{c}$ & \\
\hline & Exclusive breastfeeding at discharge & $0.896(-0.745 ; 2.536)$ & 0.279 & $1.068(-0.902 ; 3.039)$ & 0.282 & $1.594(0.073 ; 3.114)$ & 0.040 \\
\hline \multirow[t]{10}{*}{ Second } & Mother's age (years) & $-0.108(-0.274 ; 0.057)$ & 0.195 & $-0.096(-0.270 ; 0.077)$ & 0.270 & $-0.108(-0.265 ; 0.049)$ & 0.174 \\
\hline & Boy & $0.047(-1.619 ; 1.714)$ & 0.955 & $0.015(-1.568 ; 1.597)$ & 0.985 & $-c$ & \\
\hline & Primipara & $2.884(1.380 ; 4.388)$ & $<0.001$ & $2.853(1.227 ; 4.480)$ & 0.001 & $2.895(1.380 ; 4.411)$ & $<0.001$ \\
\hline & Induction of childbirth & $0.934(-1.123 ; 2.991)$ & 0.367 & $0.447(-1.495 ; 2.390)$ & 0.646 & $-c^{c}$ & \\
\hline & Caesarean section & $-0.104(-2.174 ; 1.966)$ & 0.921 & $1.802(-0.307 ; 3.911)$ & 0.092 & $1.688(-0.269 ; 3.644)$ & 0.089 \\
\hline & Night time birth & $1.105(-0.540 ; 2.751)$ & 0.184 & $2.131(0.495 ; 3.767)$ & 0.012 & $2.019(0.488 ; 3.550)$ & 0.011 \\
\hline & Gestational age (weeks) & $-0.366(-1.864 ; 1.131)$ & 0.626 & $-0.139(-1.726 ; 1.448)$ & 0.861 & $-^{c}$ & \\
\hline & Infant's birth weight $(\mathrm{kg})$ & $-3.358(-5.904 ;-0.812)$ & 0.011 & $-2.828(-5.422 ;-0.233)$ & 0.033 & $-3.001(-5.383 ;-0.618)$ & 0.014 \\
\hline & Supplementary artificial milk feeds given & $-0.612(-2.359 ; 1.135)$ & 0.486 & $-1.744(-3.897 ; 0.409)$ & 0.110 & $-1.857(-3.454 ;-0.259)$ & 0.024 \\
\hline & Exclusive breastfeeding at discharge & $0.964(-0.687 ; 2.615)$ & 0.248 & $0.278(-1.619 ; 2.174)$ & 0.770 & $-^{c}$ & \\
\hline
\end{tabular}

1 a First day: $\mathrm{R}^{2}=0.334$; second day $\mathrm{R}^{2}=0.390$.

2 birst day: $\mathrm{R}^{2}=0.321$; second day $\mathrm{R}^{2}=0.387$.

$3{ }^{\mathrm{c}}$ Not in model. 
Figure 1 (on next page)

Numbers of potential participants, participants, reasons for exclusion and attrition. 


\section{LATE PRETERM INFANTS}

BORN BETWEEN 35 0/7 - 36 6/7 COMPLETED WEEKS OF GESTATION WERE SCREENED FOR INCLUSION

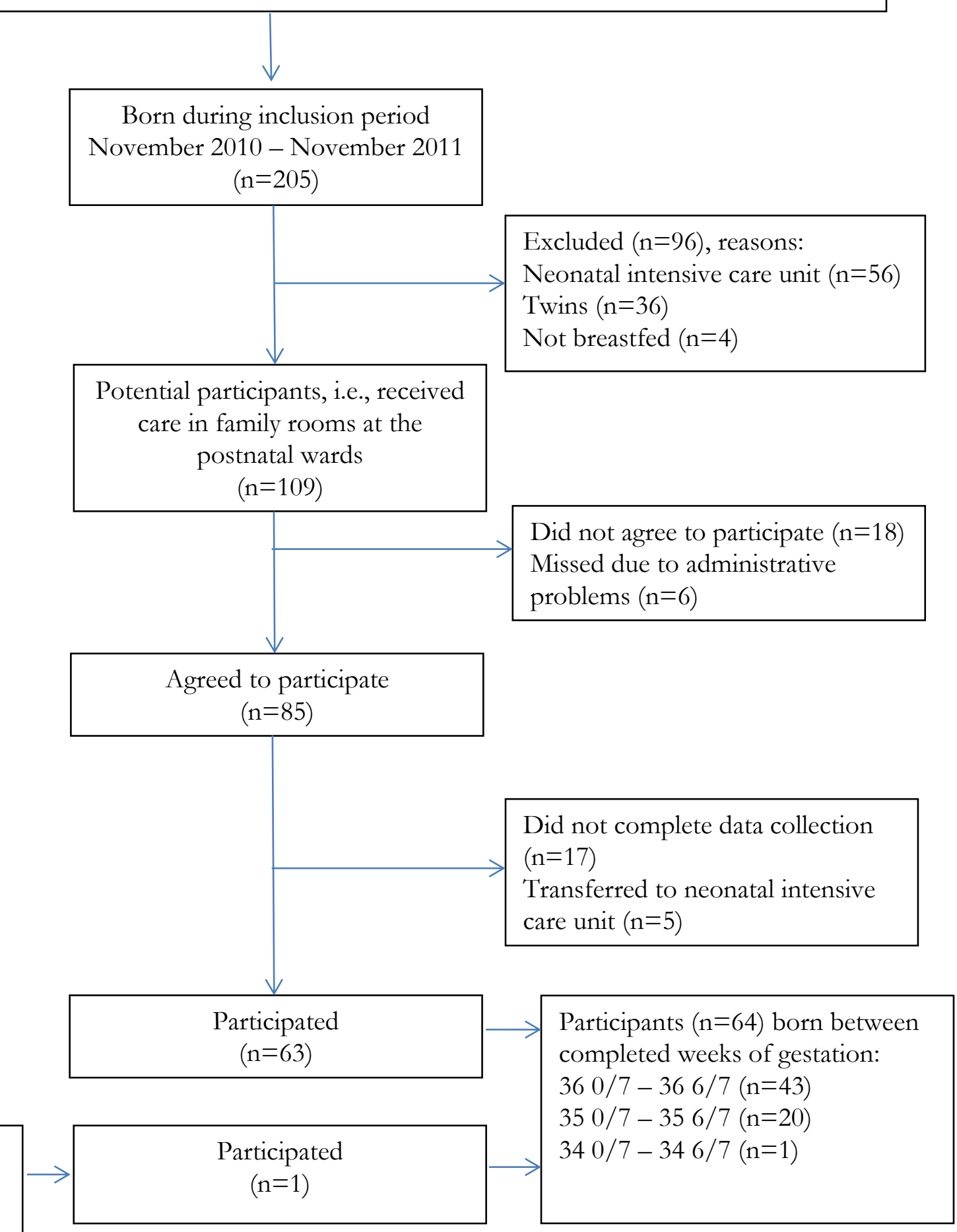

ONE LATE PRETERM

INFANT BORN BETWEEN

34 0/7 - 34 6/7 COMPLETED

WEEKS OF GESTATION

RECEIVED CARE IN A

FAMILY ROOM AT A

POSTNATAL WARD AFTER

BIRTH (INSTEAD OF THE

NEONATAL INTENSIVE

CARE UNIT)
Excluded ( $\mathrm{n}=96)$, reasons:

Neonatal intensive care unit $(\mathrm{n}=56)$

Twins ( $\mathrm{n}=36$ )

Not breastfed $(n=4)$

Did not agree to participate $(\mathrm{n}=18)$

Missed due to administrative problems $(n=6)$

Did not complete data collection 17)

Transferred to neonatal intensive care unit $(n=5)$

(n=64) born between $360 / 7-366 / 7(n=43)$ $350 / 7-356 / 7(\mathrm{n}=20)$ $340 / 7-346 / 7(n=1)$ 